\title{
Benefício Antecipado: uma nova abordagem para o tratamento com cirurgia ortognática que elimina o preparo ortodôntico convencional
}

Jorge Faber*

\begin{abstract}
Resumo
Introdução: o tratamento ortodôntico-cirúrgico convencional para correção de deformidades dentofaciais apresenta um elevado tempo de preparo ortodôntico do paciente, que, por vezes, ocasiona uma piora temporária em sua aparência. Isso fundamentou o desenvolvimento de uma nova técnica de tratamento que se destina a solucionar essas dificuldades. Objetivos: apresentar esse novo protocolo, denominado Benefício Antecipado, e ilustrá-lo com um caso clínico. Métodos: as etapas do planejamento são apresentadas e, posteriormente, ilustradas com o tratamento de um paciente portador de uma deformidade de Classe III. Nesse método, após um criterioso planejamento, o aparelho ortodôntico é montado e a cirurgia ortognática é realizada em seguida. Conclusão: apesar de ambas as técnicas - a tradicional e a de Benefício Antecipado - propiciarem excelentes resultados tanto funcionais quanto estéticos, o novo protocolo permite alcançar melhoras significativas logo ao início do tratamento. Isso é vantajoso, em especial, para os pacientes.
\end{abstract}

Palavras-chave: Cirurgia ortognática. Deformidades dentoesqueléticas. Preparo ortodôntico.

\section{INTRODUÇÃO}

O tratamento ortodôntico-cirúrgico convencional para correção de deformidades dentofaciais abrange, após o diagnóstico e o plano de tratamento, uma fase de Ortodontia pré-cirúrgica, a cirurgia ortognática propriamente dita e uma fase de finalização ortodôntica ${ }^{1}$.

Esse método de tratamento foi testado também pelo tempo - pois é implementado há décadas e é eficaz. Entretanto, ele tem limitações, pois, ao decidir realizar o tratamento, o paciente precisa esperar quase um ano e meio para realizar a cirurgia $^{2}$, bem como, na maioria dos casos, ver a sua aparência facial piorar durante esse período. Isso é um tanto paradoxal, porque muitos pacientes que procuram tratamento o fazem buscando a melhora estética $^{3,4,5,6}$, ainda que o tratamento tenha um forte cunho funcional.

Em virtude dessa limitação, desenvolvi e utilizo em minha clínica privada, desde o ano de 2004,

\footnotetext{
* Editor do Dental Press Journal of Orthodontics. Doutor em Biologia - Morfologia pelo Laboratório de Microscopia Eletrônica - UnB. Mestre em Ortodon-
} tia e Ortopedia Facial - UFRJ. 
uma metodologia de tratamento que antecipa a realização da cirurgia. Esse protocolo se baseia em, após o diagnóstico, planejar extensamente todas as fases do tratamento, montar o aparelho ortodôntico, operar o paciente e, somente depois, realizar o tratamento ortodôntico propriamente dito.

Essa metodologia antecipa os benefícios da cirurgia e por isso foi denominada de Benefício Antecipado. Ela não muda de forma significativa a técnica cirúrgica, mas sim o tratamento ortodôntico, tornando-o mais complexo, por incorporar a ancoragem esquelética na maior parte dos casos e requerer um comprometimento do ortodontista em atingir os objetivos traçados ao início.

Esse artigo visa descrever esse protocolo por meio de um relato de caso.

\section{DEFINIÇÃO DA DIREÇÃO GERAL DE UM TRATAMENTO ORTODÔNTICO-CIRÚRGICO}

O primeiro passo a ser feito é o diagnóstico, seguido pela definição da direção geral de tratamento. Por fim, é realizado o planejamento.

O diagnóstico - que requer anamnese, exames físico e complementares - é crucial. Ele orientará o cirurgião e o ortodontista sobre as necessidades do caso. Porém, o diagnóstico não se altera com o presente protocolo e, assim, sugiro a leitura de artigos específicos sobre esse tema ${ }^{7,8,9}$.

Quando o diagnóstico é estabelecido, delineiase a direção geral de tratamento. Por exemplo, uma cirurgia combinada das maxilas e mandibula para correção de uma deformidade de Classe III. Esse delineamento é discutido com o paciente e, se for o caso, também com seus responsáveis. Nem sempre um tratamento tecnicamente ideal é o indicado para aquele paciente específico. Fatores culturais, sociais e econômicos interferem na tomada de decisão do paciente. Ao profissional cabe orientar sobre as vantagens e desvantagens de cada alternativa de tratamento.

Uma vez que o paciente toma uma decisão esclarecida, o planejamento propriamente dito é realizado.

\section{PLANEJAMENTO COMBINADO DE DEFORMIDADES DENTOFACIAIS}

O planejamento do tratamento requer a integração de todas as especialidades envolvidas no caso. Dessa forma, quando se opta por tratar uma deformidade dentofacial englobando a cirurgia ortognática, teremos pelo menos dois planejamentos distintos, porém consonantes: o ortodôntico e o cirúrgico. Por vezes, também é necessário incluir os tratamentos periodontal, protético e restaurador, entre outros.

Aqui trataremos apenas dos planejamentos ortodôntico e cirúrgico.

\section{Planejamento ortodôntico}

O planejamento ortodôntico é algo complexo e, por isso, do profissional que o realiza requer-se uma longa formação. Um tratado de Ortodontia não é suficiente para abranger todos os aspectos do planejamento. Assim, não entrarei em detalhes interdisciplinares ou temas que se expandam além dos limites do tratamento de um paciente com periodonto sadio e não-reduzido, e portador de todos os dentes até os segundos molares.

Uma questão deve ser definida de pronto no traçado cefalométrico: a posição final dos incisivos superiores e inferiores. Para isso, é muito importante ter analisado criteriosamente as exposições dos incisivos em repouso e ao sorrir. A definição no traçado leva em consideração tanto as inclinações quanto as posições anteroposteriores e verticais desses dentes. Caso os planos oclusais maxilar ou mandibular forem ser alterados ortodonticamente por intrusão ou extrusão dos dentes posteriores, isso deve ser planejado nesse momento. Entretanto, essas alterações, associadas ao tratamento de mordidas abertas ${ }^{10}$, raramente são implementadas.

Uma vez estabelecidas essas posições, é necessário analisar os modelos de gesso e, por vezes, o próprio paciente. É preciso definir se há uma estrutura periodontal adequada para suportar a movimentação dentária. Além disso, em certos tratamentos precisamos avaliar se há espaço disponível para 
as movimentações dentárias. Por exemplo, quando planejamos distalizar os molares superiores, é crucial determinar se há espaço na tuberosidade para a realização do movimento. Caso as mudanças pareçam factíveis, devemos seguir adiante com o planejamento. Caso contrário, é necessário rever o planejamento desse ponto.

Definidas as posições dos incisivos, o passo seguinte é realizar um set up que simula a movimentação dentária ortodôntica desejada. Essa técnica já foi detalhadamente descrita em outras publicações $^{11,12}$. O propósito do set up é visualizar as movimentações dentárias como um todo. Pode-se, por meio dele, visualizar espaços protéticos ao final do tratamento, detectar a necessidade de extrações dentárias, ajustes das discrepâncias de Bolton, etc. Entretanto, acima de tudo, o set up permite identificar as necessidades de ancoragem do caso.

Uma vez completado o ensaio realista do tratamento, os movimentos dentários são transferidos para o traçado cefalométrico. Ou seja, traça-se os molares em suas posições inicial e final do tratamento ortodôntico.

Hoje, realizo os set ups sempre in silica, ou seja, no computador. Entretanto, utilizo exatamente os mesmos princípios que regem a realização do set up em modelos de gesso.

\section{Planejamento cirúrgico}

Uma vez que o tratamento ortodôntico é visualizado por meio do set up, pode-se realizar o planejamento da cirurgia propriamente dita. Nesse momento, já que não há um tratamento ortodôntico prévio à cirurgia, o cirurgião e o ortodontista devem levar em consideração tanto a posição dentária inicial quanto a final, após a Ortodontia. O traçado de predição cirúrgica é feito de forma similar à convencional. A diferença é que todo o planejamento deve ser feito com as posições dentárias inicial e final incluídas no traçado, mas em cores diferentes.

\section{Cirurgia ortognática}

O cerne do procedimento cirúrgico em si não sofre transformações. Entretanto, alguns detalhes precisam ser levados em consideração, tanto pelo cirurgião quanto pelo ortodontista.

$\mathrm{O}$ primeiro deles refere-se à necessidade de se utilizar uma goteira acrílica interoclusal após a cirurgia. A goteira destina-se a orientar o cirurgião em relação ao posicionamento dos fragmentos ósseos, bem como orientar o ortodontista - após a cirurgia - quanto à possível recidiva cirúrgica nos primeiros dias de pós-operatório. Isso porque qualquer alteração das relações oclusais pode ser facilmente identificada pela falta de adaptação da goteira em uma das arcadas.

O segundo detalhe está relacionado ao bloqueio intermaxilar. A definição quanto à manutenção de um bloqueio após a cirurgia depende de vários fatores que não serão discutidos aqui, como por exemplo a fragilidade dos fragmentos ósseos ou a presença de um bad split. Todavia, o bloqueio transcirúrgico é quase sempre indispensável. Dessa forma, como o paciente não é submetido à preparação ortodôntica e a cirurgia é realizada ainda nas fases iniciais de alinhamento e nivelamento, medidas específicas são necessárias para a realização do bloqueio.

Essas podem ser a confecção de um arco retangular passivo com ganchos soldados, a utilização de braquetes com ganchos em caninos e pré-molares, ou a inserção de ganchos Kobayashi. No último caso, parafusos de fixação intermaxilar podem ser necessários. Esses parafusos se assemelham a miniimplantes e são colocados diretamente no osso através da gengiva - elásticos ou fios de aço se apoiam nos parafusos. Mini-implantes ortodônticos podem ser utilizados para esse fim. E em qualquer situação, os arcos ortodônticos precisam ser amarrados com amarrilhos metálicos para evitar o risco de um amarrilho elástico se desprender e cair dentro da ferida cirúrgica.

Particularmente, não utilizo fios retangulares passivos. Os pacientes são operados, na maioria dos casos, com arcos ativos de ligas superelásticas e com ganchos Kobayashi. Devido à permanência da 
goteira acrílica cirúrgica por cerca de três semanas, a movimentação dentária ortodôntica é restringida na fase pós-operatória imediata.

\section{Limitações}

As principais limitações para a realização da cirurgia ao início do tratamento são as curvas de Spee muito acentuadas e as assimetrias verticais. Na primeira situação, a curva de Spee pode dificultar o estabelecimento de uma posição mandibular previsivel. Já nas assimetrias, é difícil uma correta avaliação do plano oclusal e das necessidades cirúrgicas de correção da assimetria, em decorrência das diferenças de alturas entre os dentes. Nos dois casos, é recomendável alinhamento e nivelamento prévios à cirurgia.

\section{RELATO DE CASO}

\section{Diagnóstico}

Paciente, gênero masculino, 18 anos e 9 meses de idade, compareceu para consulta em minha clínica privada, apresentando como queixa principal uma desarmonia facial. Sua deformidade era identificável desde criança e havia casos similares conhecidos em sua família: tia e prima em primeiro grau. A condição não apenas comprometia a função, como também a estética de maneira relevante.

A análise facial (Fig. 1) mostrou face Padrão III simétrica com perfil facial côncavo. A linha zigomaticonasolabial era sinuosa na região paranasal e interrompida ao nível da comissura labial ${ }^{7,8}$. O nariz era bem proporcionado, com o ápice nasal bem posicionado verticalmente (Fig. 4). A exposição de dentes ao sorrir era moderada.

O exame clínico intrabucal (Fig. 1) e a análise dos modelos de estudo (Fig. 2) mostraram uma relação dentária de Classe III, com apinhamentos superior e inferior.

A análise cefalométrica (Tab. 1, Fig. 4) demonstrou uma Classe III esquelética com significativo
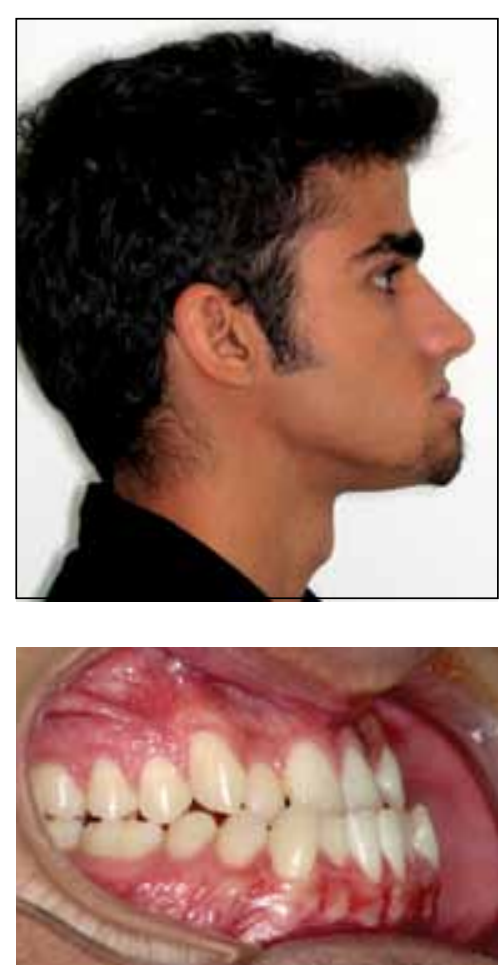

FIGURA 1 - Fotografias iniciais extra e intrabucais.
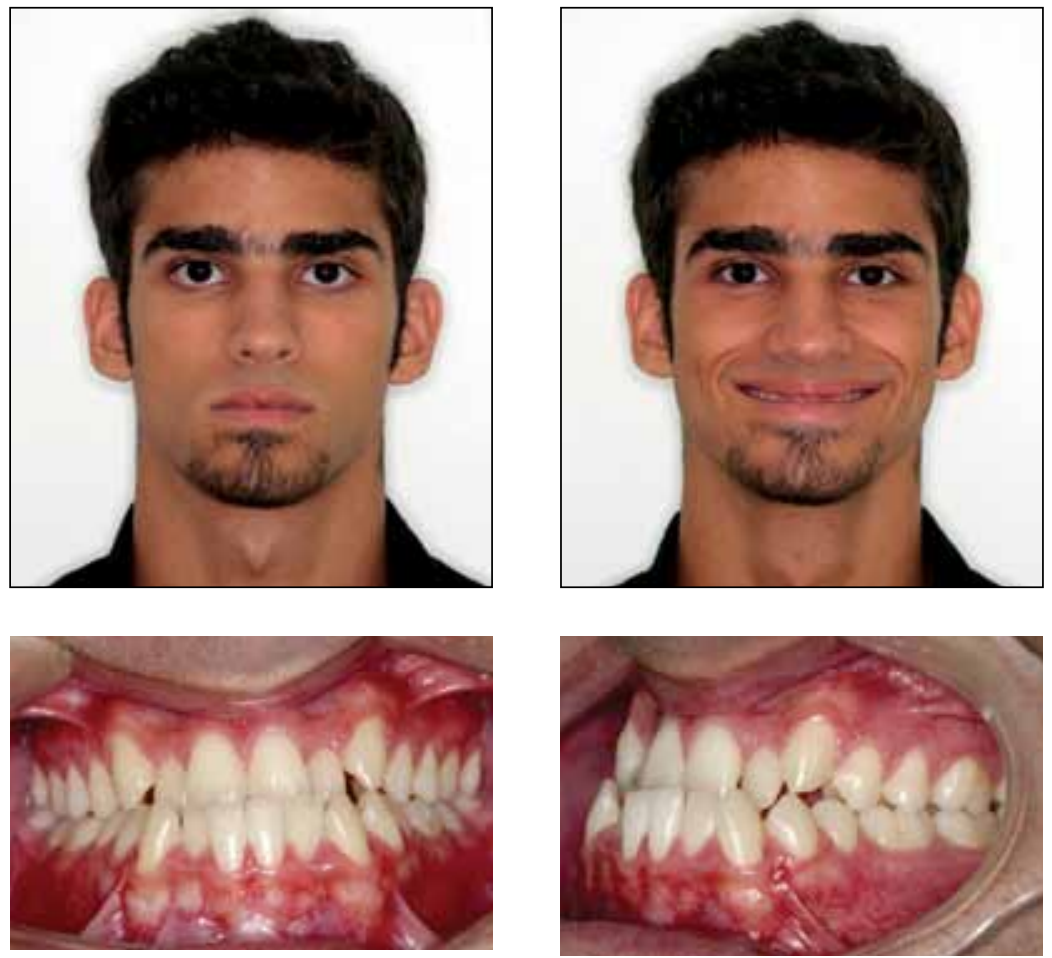

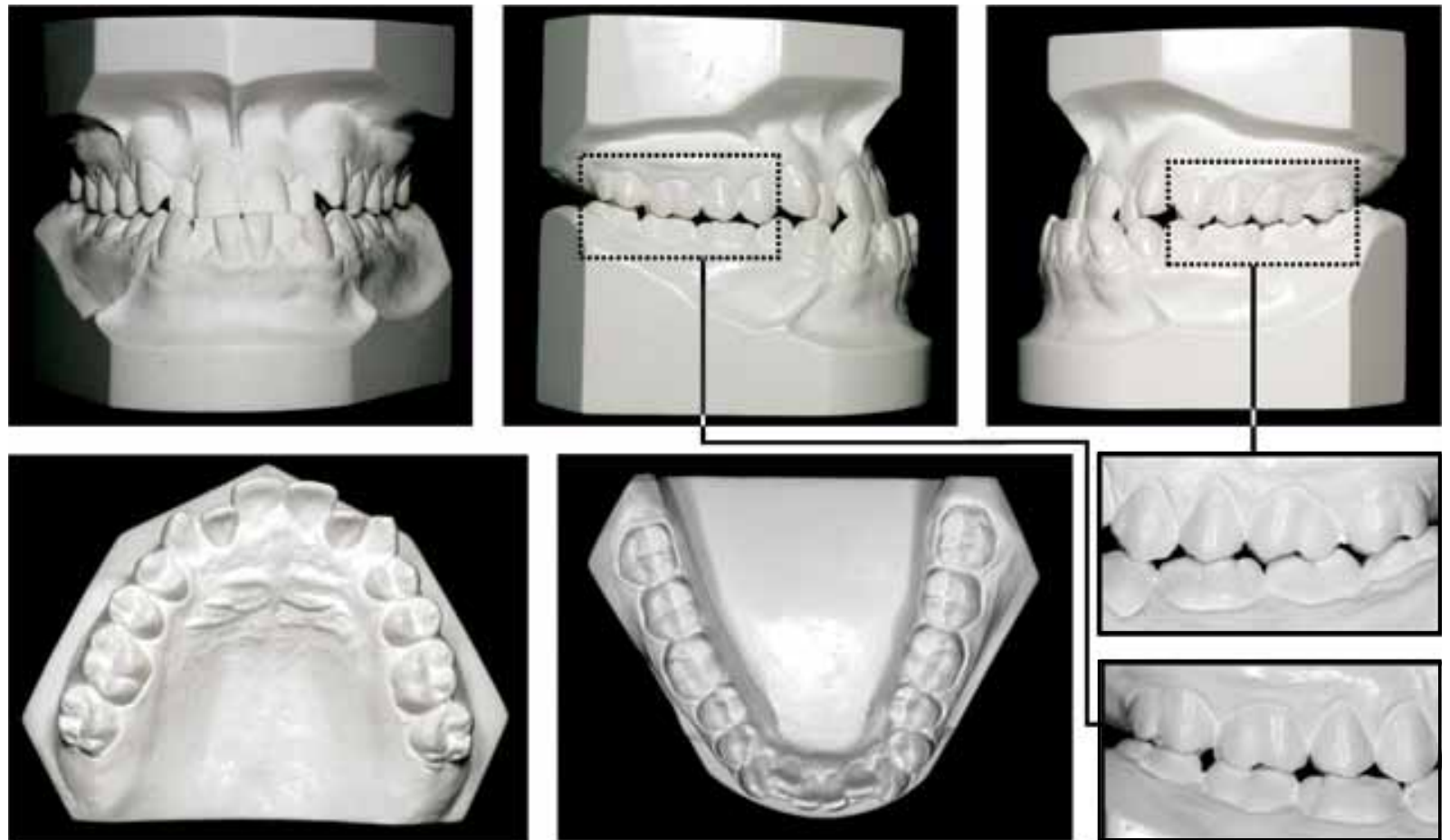

FIGURA 2 - Modelos de estudo iniciais. As áreas tracejadas estão aumentadas no canto inferior direito. Observe a relação de Classe III.

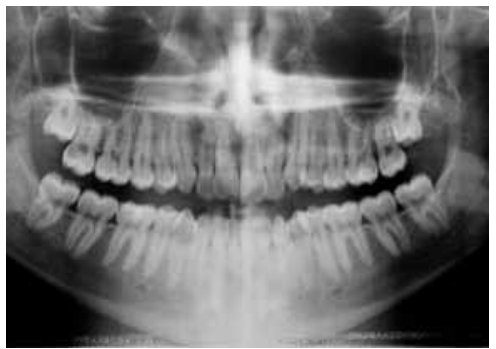

FIGURA 3 - Radiografia panorâmica inicial.
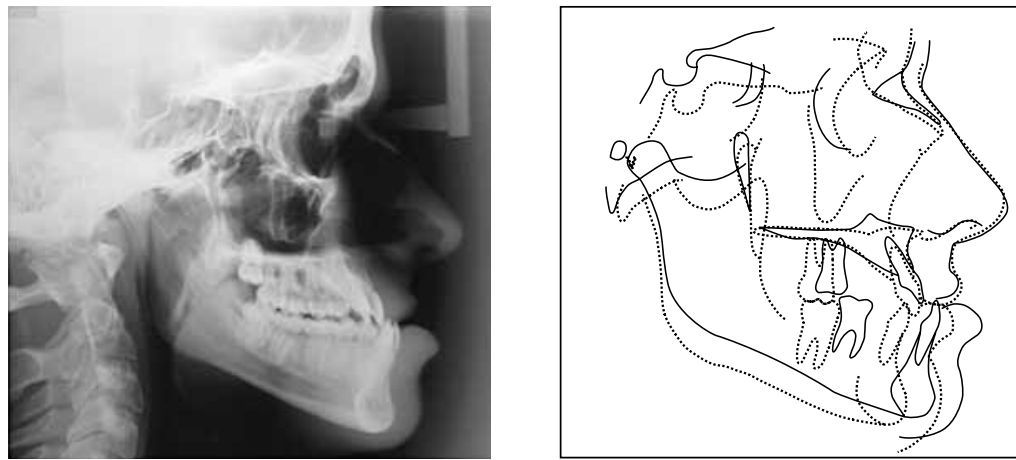

FIGURA 4 - Radiografia cefalométrica e traçado inicial (linha contínua). 0 traçado inicial está sobreposto ao traçado do padrão Bolton. Observe que a sobreposição mostra uma maxila relativamente bem posicionada no sentido anteroposterior, mas deficiente verticalmente. 0 nariz está bem proporcionado ("Bolton Standards of Craniofacial Development \& Growth", Bolton-Broadbent-Golden Case Western Reserve University - Cleveland, Ohio). 
prognatismo mandibular. Os incisivos superiores eram vestibularizados, enquanto os inferiores eram retroinclinados.

Por sua vez, a análise da radiografias panorâmica (Fig. 3), cefalométrica (Fig. 4) e periapicais da boca inteira mostrou que a deformidade de Classe III era acompanhada de boa saúde periodontal e dentária. Os terceiros molares estavam presentes.

O diagnóstico foi de uma face com Padrão III associada à má oclusão de Classe III. As relações esqueléticas eram devidas a um prognatismo mandibular significativo vinculado a deficiências anteroposterior e vertical leves a moderadas das maxilas.

\section{Opções de tratamento}

Após o diagnóstico, foi estabelecida a direção geral do tratamento. Essa consistia na correção ortodôntico-cirúrgica da deformidade associando o recuo mandibular a, possivelmente, avanço das maxilas. Todas as opções de tratamento apresentadas incluíam um tratamento ortodôntico associado à cirurgia ortognática com o protocolo de Benefício Antecipado. Os terceiros molares seriam removidos durante a cirurgia ortognática. As alternativas foram:

1. Recuo mandibular associado a avanço das maxilas. Nessa alternativa de tratamento a mandíbula seria recuada e as maxilas avançadas. Os dentes inferiores seriam projetados e os superiores retraídos.

2. Recuo mandibular associado a um enxerto paranasal. Nesse caso as maxilas não seriam avançadas, mas a região paranasal preenchida com um enxerto autógeno ou haloplástico.

3. Recuo mandibular. Nessa alternativa as maxilas não seriam avançadas e tampouco as regiões paranasais preenchidas. $\mathrm{O}$ paciente e sua família decidiram esclarecidamente por essa alternativa de tratamento.

\section{Planejamento}

O primeiro passo no planejamento foi a definição da posição final dos incisivos superiores e
TABELA 1 - Medidas cefalométricas inicial, pós-operatória e final.

\begin{tabular}{|c|c|c|c|c|}
\hline MEDIDA & VALOR & $\begin{array}{l}\text { INI- } \\
\text { CIAL }\end{array}$ & $\begin{array}{l}\text { PÓS-OPE- } \\
\text { RATÓRIO } \\
\text { (APÓS } 2 \\
\text { SEMA- } \\
\text { NAS) }\end{array}$ & $\begin{array}{l}\text { FINAL } \\
\text { (APÓS 15 } \\
\text { MESES } \\
\text { DO } \\
\text { INÍCIO) }\end{array}$ \\
\hline \multicolumn{5}{|c|}{ ANÁLISE ANTEROPOSTERIOR } \\
\hline SnV - ULP & 1 a $2 \mathrm{~mm}$ & $1 \mathrm{~mm}$ & $0 \mathrm{~mm}$ & $0 \mathrm{~mm}$ \\
\hline SnV - LLP & $0 \mathrm{a}-1 \mathrm{~mm}$ & $8 \mathrm{~mm}$ & $-3 m m$ & $-1 \mathrm{~mm}$ \\
\hline SnV - Po' & $-1 \mathrm{a}-4 \mathrm{~mm}$ & $3 \mathrm{~mm}$ & $-10 \mathrm{~mm}$ & $-6 m m$ \\
\hline $\begin{array}{c}\text { Âng. } \\
\text { nasolabial }\end{array}$ & $110^{\circ}$ & $110^{\circ}$ & $113^{\circ}$ & $108^{\circ}$ \\
\hline \multicolumn{5}{|c|}{ ANÁLISE VERTICAL } \\
\hline $1 /$ Stms & $1 \mathrm{a} 4 \mathrm{~mm}$ & $1 \mathrm{~mm}$ & $-1 \mathrm{~mm}$ & $0 \mathrm{~mm}$ \\
\hline $\mathrm{G}-\mathrm{Sn}$ & $50 \%$ & $50,4 \%$ & $48,5 \%$ & $50,7 \%$ \\
\hline$S n-M e^{\prime}$ & $50 \%$ & $49,6 \%$ & $51,5 \%$ & $49,3 \%$ \\
\hline Sn - Stms & $\begin{array}{c}33 \% \text { da } \\
1 / 2 \text { inf. }\end{array}$ & $29,8 \%$ & $30 \%$ & $30 \%$ \\
\hline Stmi - Me & $\begin{array}{c}66 \% \text { da } \\
1 / 2 \text { inf. }\end{array}$ & $70,2 \%$ & $70 \%$ & $70 \%$ \\
\hline ILG & 0 a $3 \mathrm{~mm}$ & $1 \mathrm{~mm}$ & 0 & 0 \\
\hline \multicolumn{5}{|c|}{ ANÁLISE DA POSIÇÃO DE INCISIVOS } \\
\hline $1 /-H P$ & $114^{\circ}$ a $116^{\circ}$ & $124^{\circ}$ & $125^{\circ}$ & $127^{\circ}$ \\
\hline $1 /-\mathrm{PP}$ & $110 \pm 5^{\circ}$ & $125^{\circ}$ & $125^{\circ}$ & $127^{\circ}$ \\
\hline$/ 1-$ GoMe & $95 \pm 5^{\circ}$ & $80^{\circ}$ & $81^{\circ}$ & $89^{\circ}$ \\
\hline \multicolumn{5}{|c|}{ ANÁLISE DE TECIDOS DUROS } \\
\hline NPer - A & $1 \mathrm{~mm}$ & $1 \mathrm{~mm}$ & $2 \mathrm{~mm}$ & $0,5 \mathrm{~mm}$ \\
\hline NPer - B & $-3 m m$ & $11 \mathrm{~mm}$ & $-3 m m$ & 0 \\
\hline GoGn-SN & 32 & $21^{\circ}$ & $26^{\circ}$ & $25^{\circ}$ \\
\hline
\end{tabular}

inferiores. No presente caso, optou-se por manter a posição dos incisivos superiores para não retrair o lábio superior - uma decisão fundamentada na estética -, já que o avanço das maxilas não seria realizado. Além disso, planejou-se projetar os incisivos inferiores. Todos esses movimentos dentários são similares aos que seriam realizados caso fosse tratar o paciente de forma convencional, com preparo ortodôntico.

Para definir a projeção dos incisivos inferiores, a cefalometria foi utilizada ${ }^{13}$. O incisivo inferior estava lingualizado cerca de $10^{\circ}$ (Tab. 1). Assim, programou-se uma projeção de $10^{\circ}$ (Fig. 5A, D). O lábio inferior foi projetado em $80 \%$ da movimenta- 

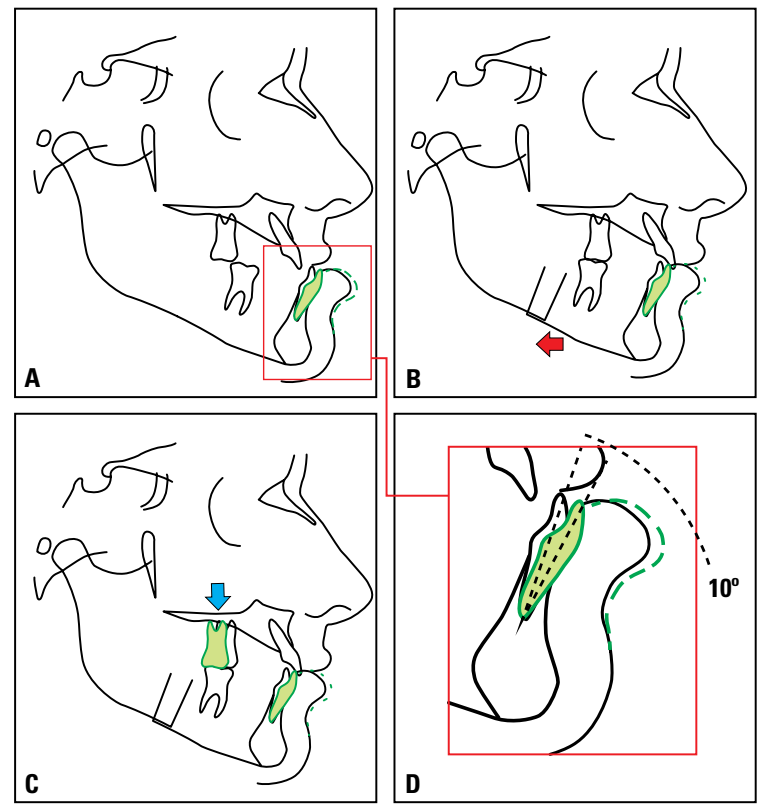

FIGURA 5 - A) Ao traçado cefalométrico inicial, em preto, está sobreposta, em verde, a posição do incisivo e do lábio inferior. 0 lábio inferior teve uma projeção prevista de $80 \%$ do movimento dentário. B) A seta vermelha realça o recuo da mandíbula até uma correta relação dos incisivos. 0 plano oclusal foi utilizado como referência para o deslize posterior da mandíbula. Observe que a relação dentária posterior torna-se de Classe II. C) Após a realização de um set up para determinar a correta relação dos dentes posteriores, eles são traçados (seta azul). Nesse caso, os incisivos superiores e os molares inferiores não alteraram suas relações anteroposteriores. 0 quadro vermelho em $\mathbf{A}$ ) está realçado em D), demonstrando a mudança de $10^{\circ}$ na angulação dos incisivos inferiores. Todo esse planejamento foi discutido e feito em conjunto com os cirurgiões que operaram o paciente (Dr. Frederico Salles e Dr. Marcos Anchieta).

ção dentária. Porém, ainda não existem bons algoritmos de previsão da movimentação dos lábios em qualquer cenário de planejamento, seja convencional ou de Benefício Antecipado.

Assim que a posição dos dentes anteriores foi definida, foi possível planejar o recuo mandibular. Ele foi feito deslizando o traçado parcial da mandíbula para posterior ao longo do plano oclusal até que a correta relação dos incisivos em suas posições finais fosse alcançada (Fig. 5B). A partir dessa nova posição, pôde-se avaliar os resultados prognosticados. É importante ressaltar que o paciente, que possuía relações de Classe III esquelética e dentária, teria suas bases ósseas posicionadas idealmente. Isso levaria - como levou - a uma face Padrão I, ou seja, com bom perfil facial. Entretanto, sua relação den- tária seria transformada em Classe II.

Em certas circunstâncias pode ser necessário, a partir desse ponto, reavaliar os resultados planejados. Eventualmente, estudar outras alternativas de tratamento se faz necessário. Essas podem incluir novas combinações de movimentação dentária e esquelética, e até requerer novas discussões entre ortodontista, cirurgião e paciente. Entretanto, não foi esse o caso no presente tratamento.

Uma vez que a posição dos dentes anteriores foi estabelecida, foi necessário - e em grande parte dos casos o é - visualizar a posição dos dentes posteriores por meio de um set up. Utilizo, há alguns anos, um procedimento de realização do set up muito similar ao feito em modelos de gesso ${ }^{11,12}$. Todavia, escaneio os modelos em um escâner 3D, segmento os dentes em um programa de computador e realizo suas movimentações. Minha experiência sugere que essa técnica requer menos tempo de trabalho do que a tradicional e permite quantas combinações de tratamento quanto se possa imaginar. Além disso, o resultado do set up pode ser prototipado, se necessário, para facilitar a comunicação com o paciente. A demonstração dessa técnica será feita em breve em outra publicação.

No tratamento que está sendo apresentado, o resultado do set up demonstrou que os movimentos planejados permitiriam uma boa relação dentária ao final do tratamento (Fig. 6). Também ficou claro que uma pequena retração dos dentes posteriores superiores seria necessária (vídeo 1, disponível em www.dentalpress.com.br/journal). O mesmo ensaio elucidou que o posicionamento dos incisivos inferiores projetados $10^{\circ}$ viabilizaria o alinhamento da arcada inferior sem necessidade de desgastes interproximais ou qualquer tipo de artifício adicional (vídeo 2, disponível em www.dentalpress.com.br/ journal).

As informações extraídas do set up foram importantes para determinar os mecanismos de ancoragem que seriam utilizados. Duas miniplacas foram planejadas na maxila para retrair todos os dentes posteriores em cerca de $2 \mathrm{~mm}$, as quais fo- 
ram instaladas durante a cirurgia ortognática. Essa movimentação dentária foi transferida para o traçado cefalométrico (Fig. 5C).

\section{Evolução e resultados do tratamento}

Após definidos os planejamentos ortodôntico e cirúrgico, o aparelho ortodôntico fixo foi montado com braquetes pré-ajustados 0,022" x 0,028" em ambos os arcos. Molares foram bandados, com exceção dos segundos molares superiores. Isso objetivou deixar o campo mais fácil para a remoção dos terceiros molares superiores. Arcos de NiTi 0,014" foram instalados imediatamente após a montagem.

A cirurgia foi realizada uma semana após a montagem do aparelho. Durante a cirurgia de recuo mandibular de $11 \mathrm{~mm}$, miniplacas foram instaladas na maxila para servir como ancoragem para retração dos dentes posteriores superiores. Os terceiros molares foram removidos.

Um goteira acrílica interoclusal foi confeccionada, servindo como referência em dois momentos: primeiro, para estabelecer a relação dos fragmentos durante a cirurgia; depois, para acompanhar clinicamente a estabilidade cirúrgica por um período de três semanas.

A aparência facial duas semanas após a cirurgia revelou uma importante melhora no aspecto facial (Fig. 7). A relação dentária após a cirurgia foi de Classe II, mas com uma face Padrão I. Os apinhamentos anteriores superior e inferior estavam inalterados (Fig. 7). O recuo mandibular foi expressivo e acarretou alterações cefalométricas importantes (Tab. 1, Fig. 8).

Após o período pós-operatório de três semanas, molas de NiTi foram aplicadas das miniplacas para os caninos superiores. Tubos foram colados nos segundos molares e esses dentes incluídos no tratamento. A ativação teve a finalidade de distalizar os dentes posteriores, provendo espaço para o alinhamento anterossuperior. As molas foram mantidas enquanto se evoluía os fios de alinhamento e nivelamento. $\mathrm{Na}$ arcada inferior, os arcos foram gradati-

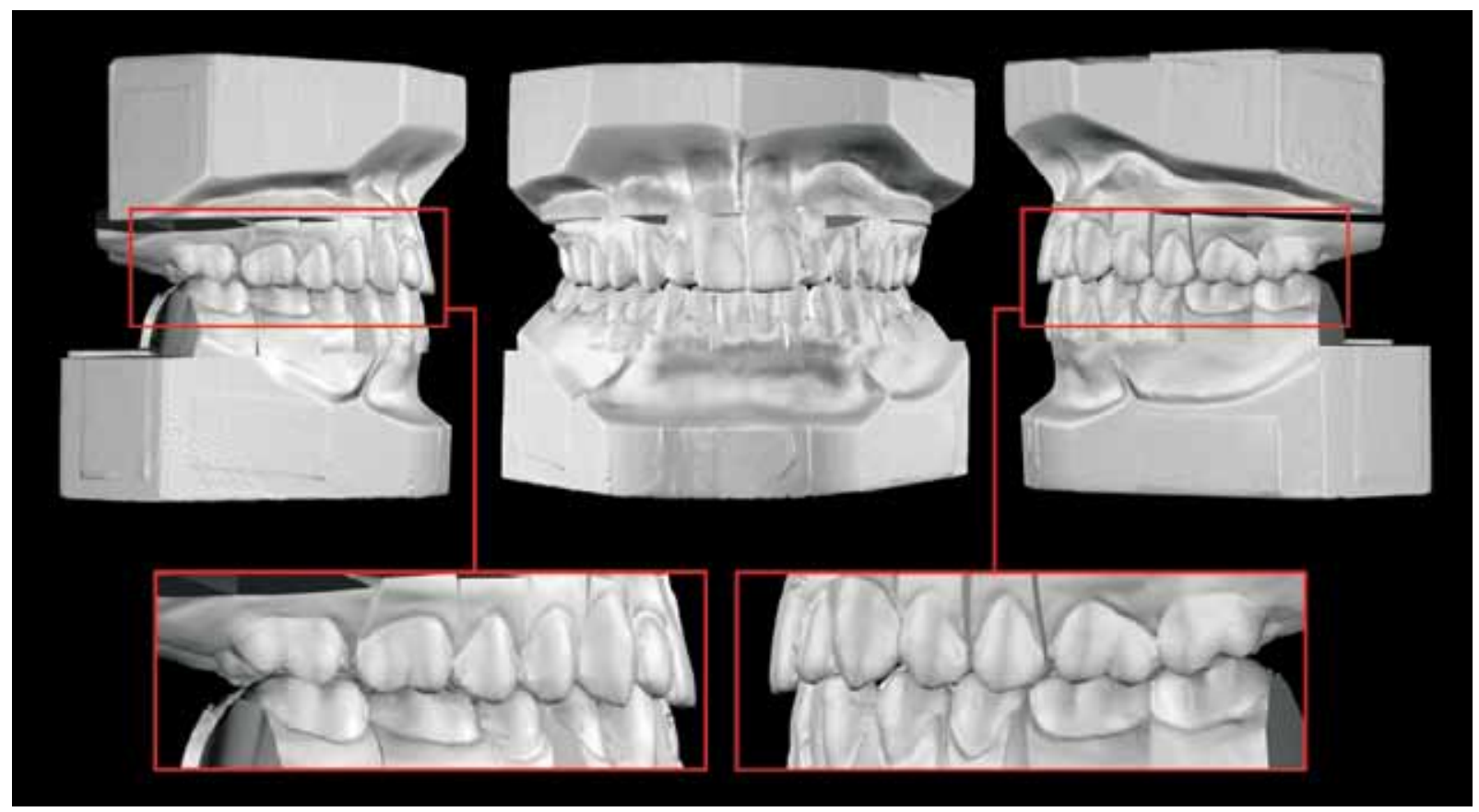

FIGURA 6 - Set up ortodôntico cirúrgico do tratamento realizado em computador. Os modelos de estudo foram escaneados em um escâner 3D, os dentes seccionados em um programa de computador, e as movimentações dentárias executadas. Os passos gerais de realização do set up virtual não diferem de maneira importante daqueles realizados em modelos físicos. Os quadros em vermelho mostram detalhes da relação dos dentes após a movimentação dentária e o recuo mandibular propostos. 

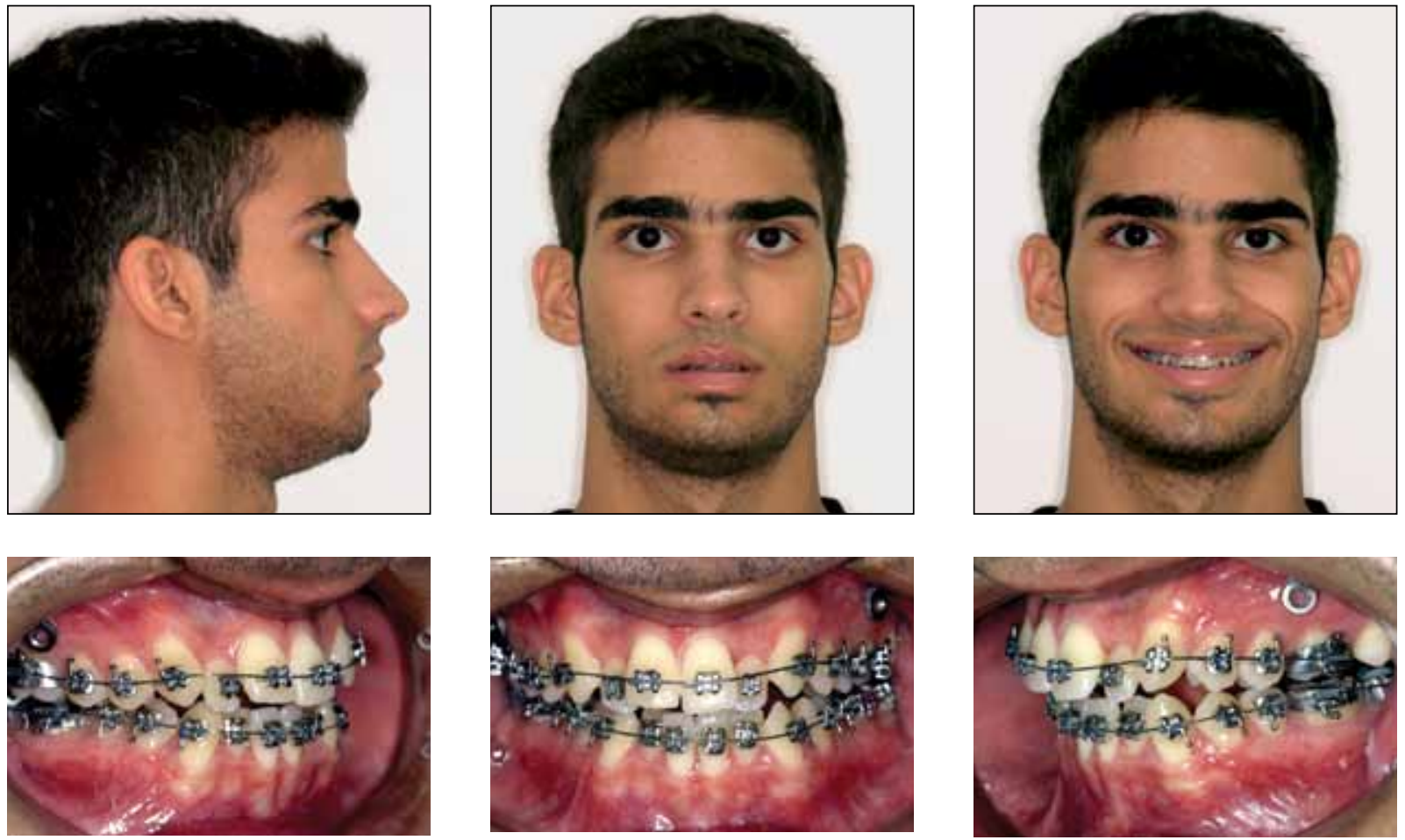

FIGURA 7 - Aparência facial duas semanas após a cirurgia, ainda com edema. A má oclusão que o paciente apresentava após a cirurgia era uma Classe II, entretanto, o mesmo já possuía uma face Padrão I (paciente operado pelos Drs. Frederico Salles e Marcos Anchieta).
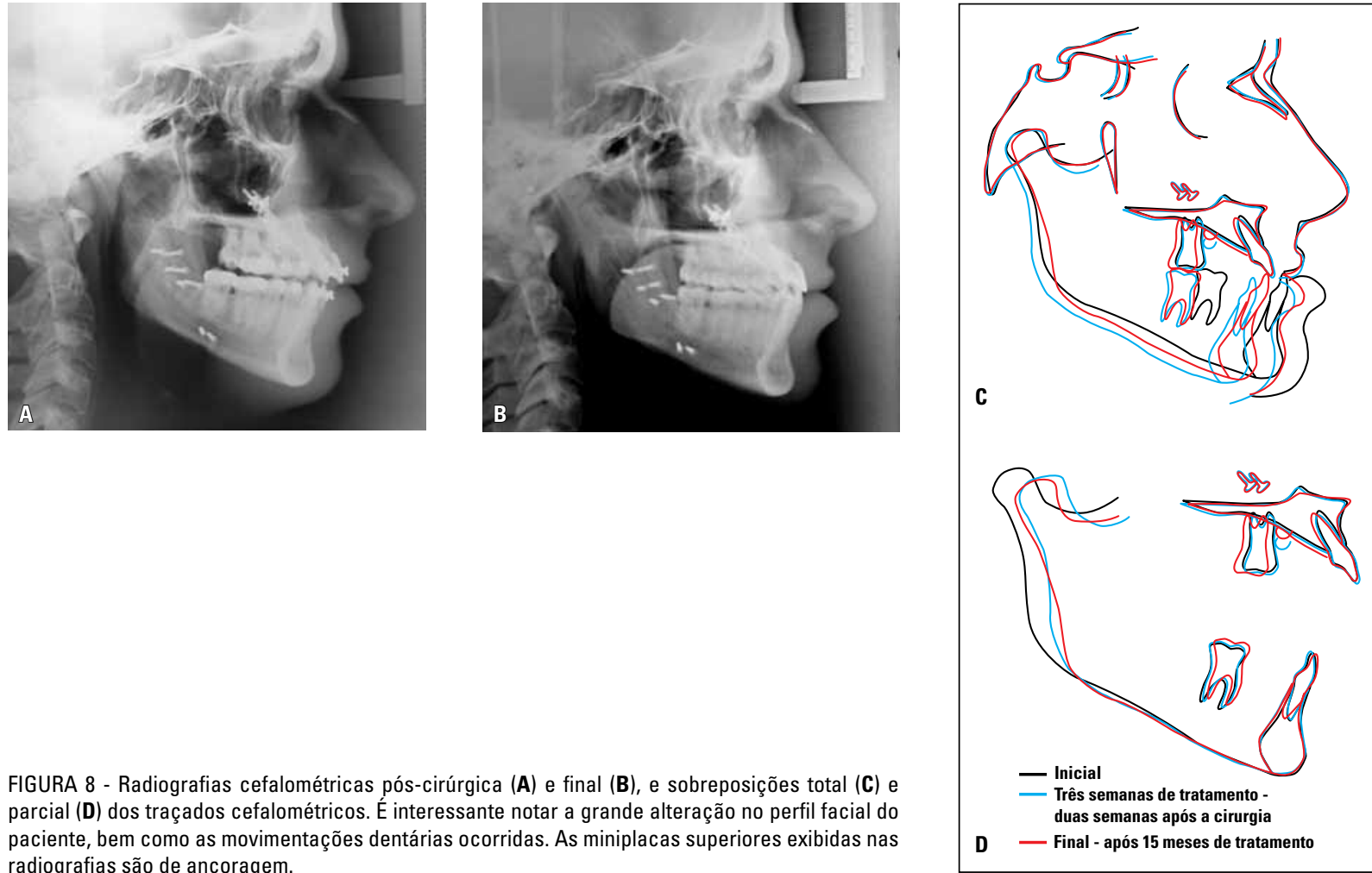
FIGURA 8 - Radiografias cefalométricas pós-cirúrgica (A) e final (B), e sobreposições total (C) e
parcial (D) dos traçados cefalométricos. É interessante notar a grande alteração no perfil facial do paciente, bem como as movimentações dentárias ocorridas. As miniplacas superiores exibidas nas radiografias são de ancoragem. 

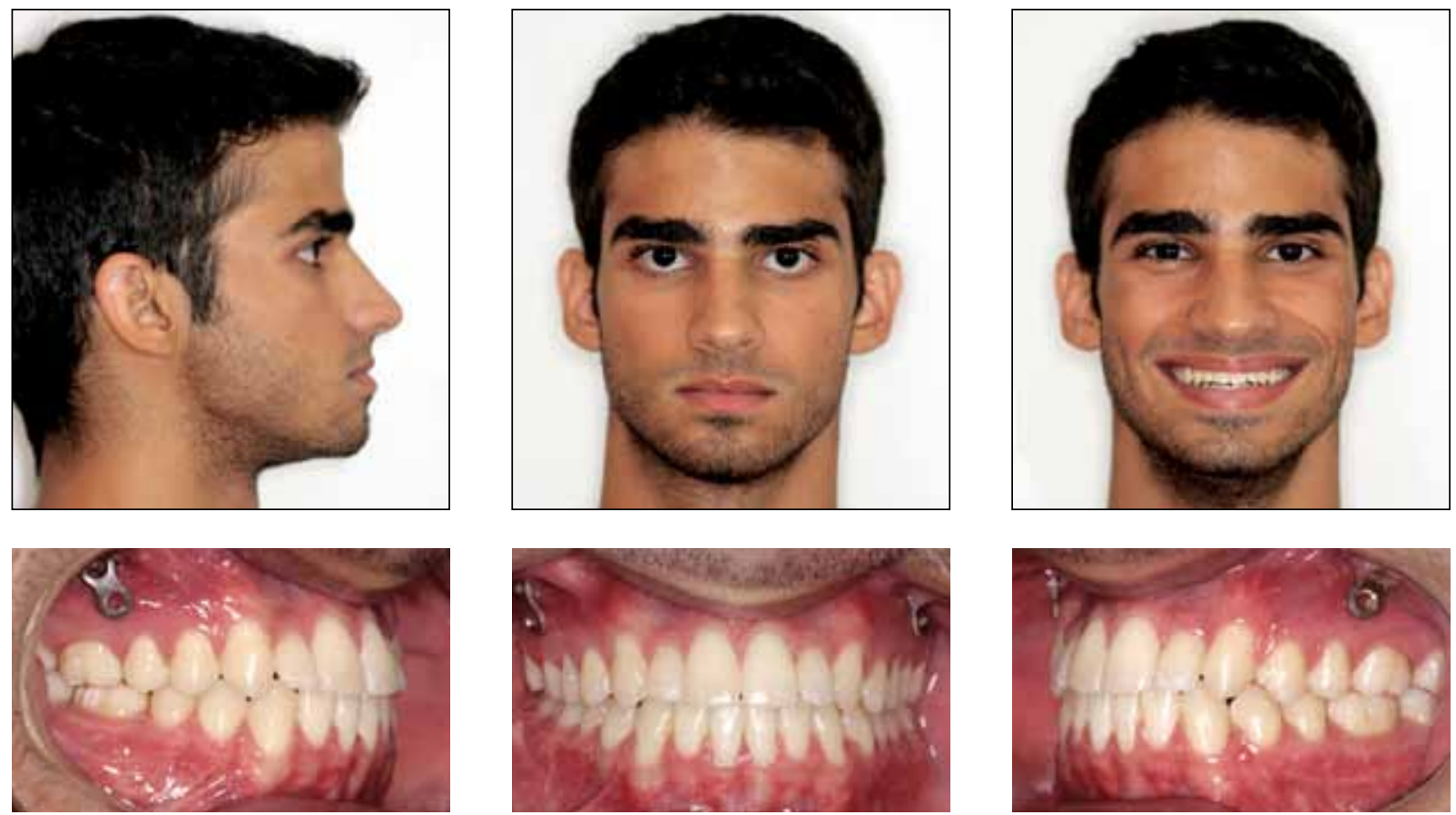

FIGURA 9 - Fotografias finais extra e intrabucais (cirurgia realizada pelos Drs. Frederico Salles e Marcos Anchieta).
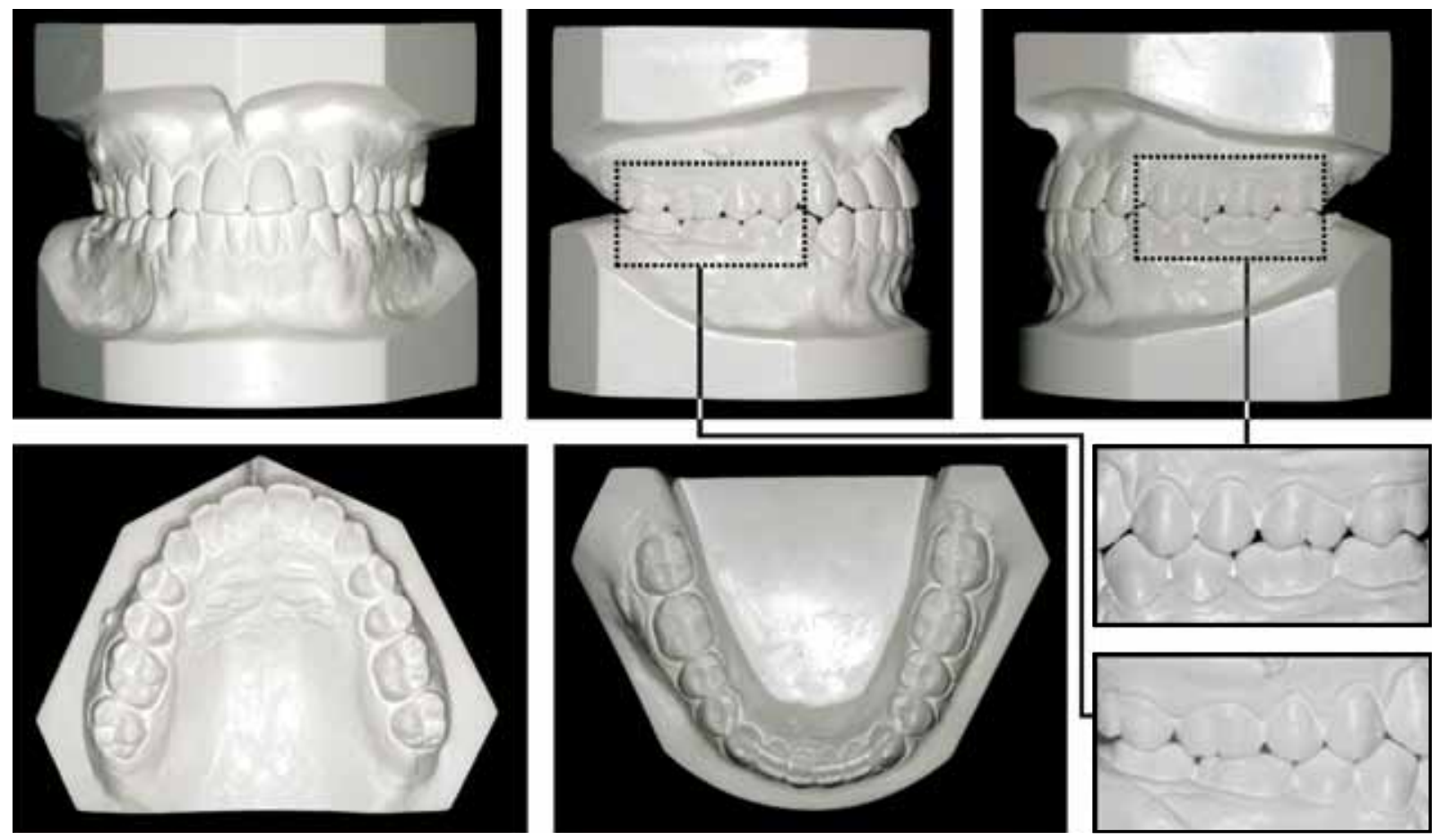

FIGURA 10 - Modelos de estudo finais. As áreas tracejadas estão aumentadas no canto inferior direito. Observe a relação dos molares. 


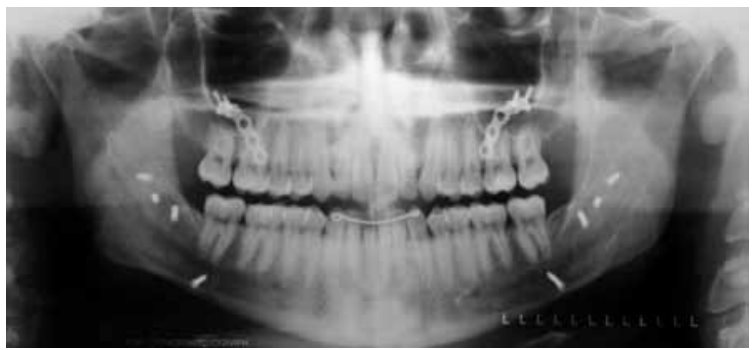

FIGURA 11 - Radiografia panorâmica final.

vamente evoluídos de um 0,014 " de NiTi para um arco em aço 0,017 " x 0,025”.

$\mathrm{Na}$ fase de finalização, elásticos intermaxilares foram utilizados por curto período para melhorar a intercuspidação. $\mathrm{O}$ resultado final do tratamento agradou muito o paciente, tanto no que tange a aparência facial quanto a oclusão. $\mathrm{O}$ aparelho foi removido com 15 meses de tratamento e foram instalados um aparelho removivel superior tipo wraparound e uma contenção fixa inferior $3 \times 3$.

Dois anos após o tratamento (Fig. 12), a oclusão continuava estável.

\section{DISCUSSÃO}

O tratamento ortodôntico-cirúrgico pela técnica do Benefício Antecipado traz vantagens para os pacientes que se submetem a essa modalidade de tratamento. Essas vantagens advêm da eliminação do período de preparo ortodôntico convencional, antecipando o ansiado momento cirúrgico. Ao final, com ambas as técnicas alcançamos excelentes resultados tanto funcionais quanto estéticos (Fig. 13C, 14C), contudo, o adiantar da cirurgia oferece um tratamento mais focado no paciente. Sua aplicação se justifica, pois, com o novo protocolo, podese proporcionar melhoras significativas ao início do tratamento (Fig. 14A, B), tanto em problemas graves de saúde como a apneia, quanto em questões estéticas da face.

O paciente, assim, não vivencia a piora no aspecto facial que acompanha a maior parte dos tratamentos convencionais (Fig. 13A, B), especialmente, das deformidades de Classe III. A piora associada ao tratamento convencional é, de certa forma, paradoxal. Sabe-se que boa parte dos pacientes que busca a cirurgia ortognática o faz por razões estéticas ${ }^{3-6}$, ainda que a cirurgia acarrete comprovados ganhos funcionais ${ }^{14}$. Todavia, para alcançar os ganhos estéticos, o paciente tem que piorar - transitoriamente, por um período médio de 17 meses $^{2}$ - sua aparência facial.

A essência dessa técnica se baseia em um planejamento ortodôntico muito cuidadoso. Ela obviamente não altera o diagnóstico das deformidades dentofaciais, mas torna o ato do planejamento mais laborioso, pois incorpora a necessidade de visualização dos objetivos da Ortodontia no traçado cefalométrico e no set up.

O set up em si é importante para determinar a posição final dos dentes posteriores. Essa previsão é relevante não por uma curiosidade acadêmica, é ela que auxilia o ortodontista no entendimento da oclusão final do paciente, bem como na identificação das necessidades de ancoragem. Porém, o set up não é crucial em todos os casos, pois a experiência do profissional em tratar problemas similares pode suplantar sua necessidade.

Talvez, uma regra geral em relação ao set up seja que ele deve ser feito toda a vez que existe dúvida quanto a certos pontos do tratamento, em especial à ancoragem e aos espaços protéticos. No Benefício Antecipado, a ancoragem esquelética é fundamental em muitos casos, mas não em todos.

Minha experiência mostra que o uso de miniplacas como ancoragem é vantajoso para muitos tratamentos, como o relatado nesse artigo. Algo semelhante foi publicado recentemente em outro $\operatorname{artigo}^{15}$. Entretanto, em certos casos, mini-implantes podem ser empregados, ou mesmo não ser necessária qualquer ancoragem esquelética. Todavia, não podemos esquecer que o advento da ancoragem esquelética possibilitou a introdução de maior previsibilidade da movimentação dentária ortodôntica $^{10,16,17}$. Isso é o que viabiliza que o movimento dentário - que seria realizado antes da cirurgia, pelo método convencional de tratamento - possa, 

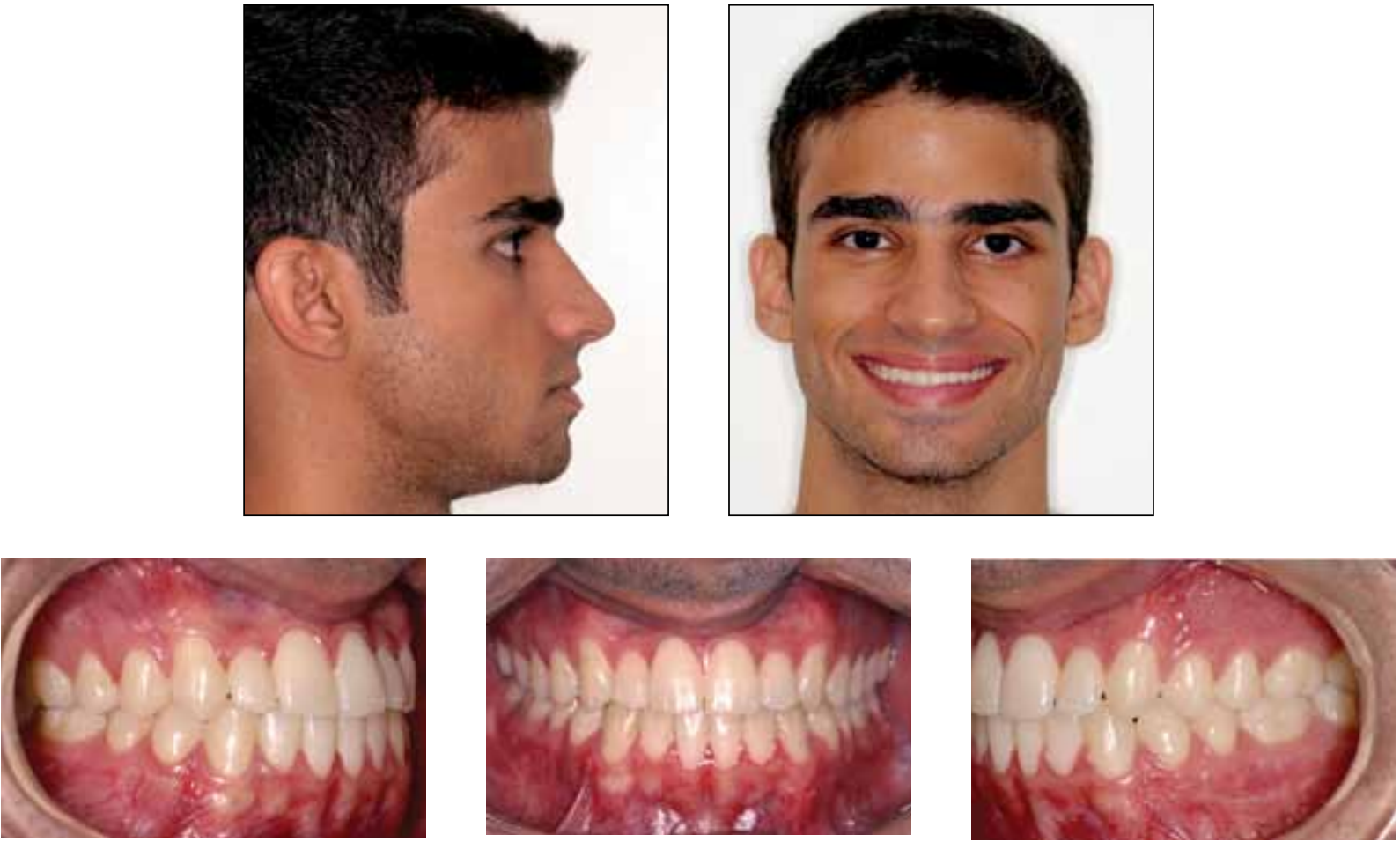

FIGURA 12 - Fotografias extra e intrabucais dois anos após o fim do tratamento (paciente operado pelos Drs. Frederico Salles e Marcos Anchieta).
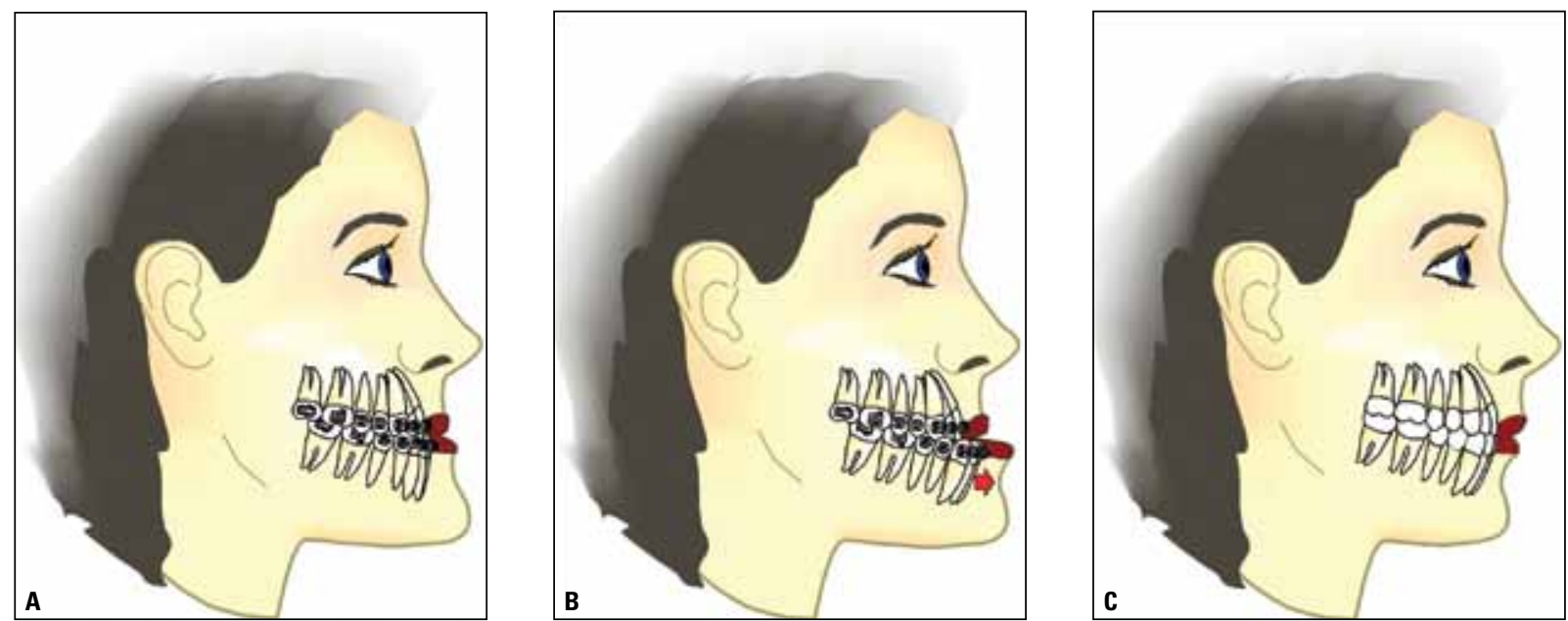

FIGURA 13 - Tratamento ortodôntico-cirúrgico pelo método convencional. A) llustração esquemática de uma deformidade de Classe III. Após o preparo ortodôntico (B), com movimentação dos incisivos inferiores para anterior (seta), há um agravamento no Padrão III facial. 0 resultado final do tratamento (C) é muito equilibrado.

em muitos tratamentos, ser feito após a cirurgia ortognática.

Ainda que o planejamento ortodôntico seja algo mais complexo que o tratamento convencional, o cirúrgico não o é. Porém, o cirurgião precisa estar muito ciente de todos os passos ortodônticos que serão dados ao longo do tratamento. Isso significa que deve haver maior harmonia entre o ortodontis- 

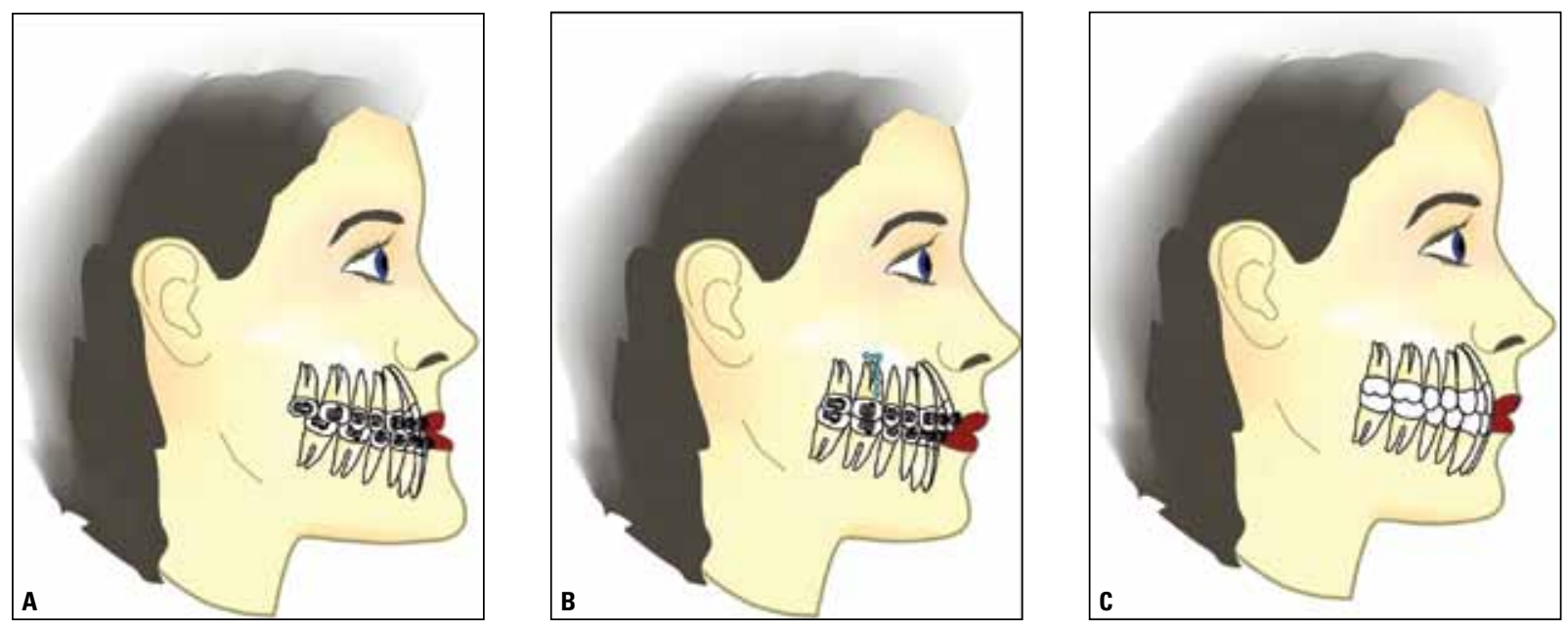

FIGURA 14 - Esquema de um tratamento ortodôntico-cirúrgico de Benefício Antecipado. A) Ao início do tratamento. Em B) temos a deformidade logo após a cirurgia ortognática, sem preparo ortodôntico convencional. Há uma mudança importante na face para um Padrão l, entretanto, os lábios ainda não têm uma correta relação. Miniplacas estão posicionadas nesse esquema para retrair os dentes superiores. Em C) temos o resultado final do tratamento. Ele tende a ser igual àquele obtido pelo método convencional.

ta e o cirurgião do que no tratamento convencional. O ortodontista precisa confiar que o cirurgião será capaz de executar aquilo que foi planejado, e o cirurgião, por sua vez, precisa estar seguro de que o ortodontista finalizará a oclusão do paciente a partir de uma relação como a apresentada na figura 7.

É importante destacar que o tratamento pelo Benefício Antecipado causa mudanças cirúrgicas das relações dentárias que diferem muito daquelas do tratamento convencional. No novo método, trocamos um tipo de má oclusão por outro e, a seguir, tratamos a nova má oclusão (Fig 14A, B). Em outras palavras, devido ao padrão típico das posições dentárias nas deformidades de Classe III, após a cirurgia, o paciente terá um Padrão I facial, mas uma má oclusão que tenderá a ser, ou será, uma Classe II (Fig. 14A, B, C). O contrário é verdadeiro para as deformidades de Classe II.

Isso quer dizer que o padrão geral de movimentos dentários realizados nessa nova modalidade de tratamento é muito similar ao feito pelo método convencional. No entanto, a movimentação dentária ortodôntica tende a ser mais rápida. Provavelmente isso ocorre porque os movimentos dentários são favorecidos pela força muscular, ao invés de irem contra ela, como no tratamento convencional. Também é provável que esse fator explique, ao menos parcialmente, a grande rapidez de quase todos os tratamentos realizados por essa abordagem.

\section{CONCLUSÃO}

Em síntese, o tratamento ortodôntico-cirúrgico de Benefício Antecipado utiliza os princípios já estabelecidos na literatura odontológica para inverter os tempos de tratamento, antecipando a realização da cirurgia. Ele é vantajoso por proporcionar melhorias estéticas e funcionais mais rápidas para o paciente, e evitar a piora transitória na estética facial que acompanha muitos tratamentos de deformidades dentofaciais.

\section{AGRADECIMENTOS}

Agradeço aos Drs. Frederico Salles, Marcos Anchieta, João Milki Neto e Rogério Zambonato Freitas pelo trabalho em equipe e por devotar sua expertise ao tratamento dos pacientes pelo protocolo de Benefício Antecipado; à Dra. Carla Virgínia Araújo Vasconcelos pelo atendimento do paciente 
aqui apresentado durante alguns meses em Fortaleza-Ceará; à Dra. Lilian Fonseca pelo auxílio na produção das ilustrações desse artigo, e à Dra. Patrícia Berto por sua crítica e minuciosa revisão desse artigo e por sua participação no atendimento dos pacientes tratados pela técnica de Benefício Antecipado.

\title{
Anticipated Benefit: a new protocol for orthognathic surgery treatment that eliminates the need for conventional orthodontic preparation
}

\begin{abstract}
Introduction: Conventional orthodontic-surgical treatment for the correction of dentofacial deformities takes up a lengthy period of time preparing the patient orthodontically, which sometimes causes a temporary deterioration in the patient's appearance. This fact has set the stage for the development of a new treatment technique aimed at addressing these issues. Objectives: To introduce a new protocol - named Anticipated Benefit - and to illustrate it with a clinical case. Methods: The planning stages are presented and then illustrated by treating a patient with a Class III deformity. According to this method, after some careful planning the orthodontic appliance is fixed and subsequently orthognathic surgery is performed. Conclusion: Although both the traditional and the Anticipated Benefit techniques provide excellent functional and aesthetic results, the new protocol achieves significant improvements soon after the start of treatment. The new method has proved very convenient, particularly for the patient.
\end{abstract}

Keywords: Orthognathic surgery. Dentofacial deformities. Orthodontic preparation.

\section{REFERÊNCIAS}

1. Jacobs JD, Sinclair PM. Principles of orthodontic mechanics in orthognathic surgery cases. Am J Orthod. 1983; 84:399-407.

2. Luther F, Morris DO, Hart C. Orthodontic preparation for orthognathic surgery: How long does it take an why? Br J Oral Maxillofac Surg. 2003 Dec;41(6):401-6.

3. Ambrizzi DR, Franz SA, Pereira Filho VA, Gabrielli MAC, Gimenez CMM, Bertoz FA. Avaliação das queixas estético-funcionais em pacientes portadores de deformidades dentofaciais. Rev Dental Press Ortod Ortop Facial. 2007 set/out;12(5):63-70.

4. Forssell H, Finne K, Forssell K, Panula K, Blinnikka LM. Expectations and perceptions regarding treatment: a prospective study of patients undergoing orthognathic surgery. Int J Adult Orthodon Orthognath Surg. 1998;13(2):107-13.

5. Vargo JK, Gladwin M, Ngan P. Association between ratings of facial attractiveness and patients motivation for orthognathic surgery. Orthod Craniofac Res. 2003 Feb;6(1):63-71.

6. Williams AC, Shah H, Sandy JR, Travess HC. Patients motivations for treatment and their experiences of orthodontic preparation for orthognathic surgery. J Orthod. 2005 Sep;32(3):191-202.

7. Arnett GW, Bergman RT. Facial keys to orthodontic diagnosis and treatment planning - part I. Am J Orthod Dentofacial Orthop. 1993;103:299-312.

8. Arnett GW, Bergman RT. Facial keys to orthodontic diagnosis and treatment planning - part II. Am J Orthod Dentofacial Orthop. 1993;103:395-411.

9. Arnett GW, Gunson MJ. Facial planning for orthodontists and oral surgeons. Am J Orthod Dentofacial Orthop. 2004;126:290-5.

10. Faber J, Morum TFA, Leal S, Berto PM, Carvalho CK dos S. Miniplates allow efficient and effective treatment of anterior open bites. Rev Dental Press Ortod Ortop Facial. 2008 set/out;13:144-57.
11. Bolognese AM. Set-up: uma técnica de confecção. Rev SOB 1995;2:245-9.

12. Tavares CAE, Zanini LK. A confecção do "Set Up" de diagnóstico ortodôntico. Rev Dental Press Ortod Ortop Facial. 1999 set/ out; $4(5): 20-3$

13. Bell WH, Jacobs JD, Quejada JG. Simultaneous repositioning of the maxilla, mandible, and chin treatment planning and analysis of soft tissues. Am J Orthod. 1986 Jan;89(1):28-50.

14. Turnbull NR, Battagel JM. The effects of orthognathic surgery on pharyngeal airway dimensions and quality of sleep. J Orthod. 2000 Sep;27(3):235-47.

15. Nagasaka H, Sugawara J, Kawamura H, Nanda R. "Surgery first" skeletal Class III correction using the Skeletal Anchorage System. J Clin Orthod. 2009 Feb;43(2):97-105.

16. Janssen KI, Raghoebar GM, Vissink A, Sandham A. Skeletal anchorage in Orthodontics: a review of various systems in animal and human studies. Int J Oral Maxillofac Implants. $2008 \mathrm{Jan} /$ Feb;23(1):75-88.

17. Yao CCJ, Lai EHH, Chang JZC, Chen I, Chen YJ. Comparison of treatment outcomes between skeletal anchorage and extraoral anchorage in adults with maxillary dentoalveolar protrusion. Am J Orthod Dentofacial Orthop. 2008 Nov;134(5):615-24.

\section{Endereço para correspondência} Jorge Faber

Brasília Shopping Torre Sul sala 408

CEP: 70.715-900 - Brasília/DF

E-mail: faber@dentalpress.com.br 